\title{
Article \\ Unravelling Theory: Strategic (Non-) Disclosure of Online Ratings
}

\author{
David Butler $^{1}$ and Daniel Read ${ }^{2, *(D)}$ \\ 1 Department of Economics, University College Cork, T12YN60 Cork, Ireland; David.Butler@ucc.ie \\ 2 Warwick Business School, University of Warwick, Coventry CV4 7AL, UK \\ * Correspondence: Daniel.Read@wbs.ac.uk
}

check for

updates

Citation: Butler, D.; Read, D.

Unravelling Theory: Strategic (Non-) Disclosure of Online Ratings. Games 2021, 12, 73. https://doi.org/ $10.3390 / 12040073$

Academic Editors: Ola Andersson and Ulrich Berger

Received: 21 June 2021

Accepted: 23 September 2021

Published: 30 September 2021

Publisher's Note: MDPI stays neutral with regard to jurisdictional claims in published maps and institutional affiliations.

Copyright: (C) 2021 by the authors. Licensee MDPI, Basel, Switzerland. This article is an open access article distributed under the terms and conditions of the Creative Commons Attribution (CC BY) license (https:/ / creativecommons.org/licenses/by/ $4.0 /)$.

\begin{abstract}
This paper investigates disclosure by testing if the game theoretic predictions of unravelling theory are borne out in a heretofore unstudied market. We analyse TripAdvisor disclosures from hoteliers across 22 locations $(N=4357)$ and consider the relationship between disclosure and industry (star) certification. Contrary to theoretical predictions, we find that disclosure decreases linearly with TripAdvisor ratings $\mathrm{n}$. We also find the same pattern of disclosure occurs when consumers know the information provider has information to disclose, and when they do not. We also find evidence suggesting the most elite hotels may disclose less. We provide practical as well as theoretical implications.
\end{abstract}

Keywords: disclosure; TripAdvisor; unravelling of information

\section{Introduction}

In modern markets, the providers of goods and services have widespread opportunities to easily display detailed information concerning their quality. A key principle in game theory predicts they will all take this opportunity, yet many do not. According to the game theoretic account, if service providers do not display certain information, rational consumers should deduce that their services are of extremely poor quality. Consequently, those service providers will always display relevant information [1-7]. For reasons that will become clear, the basis of this theory is referred to as "unravelling" - the logical reasoning process which leads service providers to conclude that disclosure is the best strategy. In theory, unravelling results in a separating equilibrium, in that even when there are information differences, the information holder feels compelled to disclose [8].

Previous empirical field tests of unravelling theory have shown incomplete disclosure. Most of these tests, however, involve small sample sizes, are limited to a geographically contained market and/or have not clearly established if the assumptions underlying unravelling theory are correct. Furthermore, past tests have not considered the effects of a violation of the model's assumptions. We contribute to the disclosure literature by overcoming these data limitations, assessing how a signal diffuses internationally and evaluating several of the assumption's underlying unravelling theories. We draw on an extensive dataset where a point-of-sale disclosure is virtually costless, documenting online TripAdvisor admissions from 4357 hoteliers in regional and international markets.

This market offers a useful (and economically important ${ }^{1}$ ) setting to consider unravelling theory and the supply side of information provision. First, TripAdvisor is an extremely familiar platform. It is a primary third-party rating agency for hotels and for many years a recognised source for electronic-word-of-mouth. We can rely on most consumers knowing about TripAdvisor and knowing that hotels possess a TripAdvisor rating. This speaks to some possible objections to earlier work-if many consumers do not know that a provider possesses some information, then the provider faces less pressure to disclose and, in many cases, will be better off not disclosing. Second, this sector is dominated by e-commerce, where disclosure is effectively costless. Disclosure simply 
involves a hotel embedding preformatted TripAdvisor code into their website. This is not a technically challenging task, nor does it involve sacrificing significant space on a website. Finally, unravelling assumes consumers lack complete information and so the rating is informative. We are confident this is true for hotel stays, which typically involve travel to a location/accommodation about which guests have limited knowledge. Given this problem, trust-based websites such as TripAdvisor have emerged and influence consumer choice by offering easily interpretable scales. This serves to reduce uncertainty for consumers when information is incomplete [9-13]. Although consumers can access TripAdvisor by themselves, if they believe hotels are rational strategic actors, they will assume hotels will disclose ratings. As an online platform, TripAdvisor is the most important forum in the tourism industry and the one subject to most academic attention. The collective judgements provided by the website influence consumer choice. For example, research has shown a positive relationship between the information posted on TripAdvisor and offline hotel popularity. Torres, Singh \& Robertson-Ring [14] find that encouraging online reviews and the number of reviews positively affected booking transactions. Xie, Chen \& Wu [15] show that the impact of review quality on TripAdvisor can last for a minimum of two quarters. Viglia, Minazzi \& Buhalis [16] demonstrate that a one-point increase in review scores increases occupancy rates by 7.5 percentage points and show that the disclosure we assess in this paper-the review score-has the highest impact on occupancy relative to other information posted online.

Our key theoretical insights are derived from our assessment of the assumptions underlying unravelling. Specifically, past tests of unravelling theory are silent on the topic of consumer expectations. A key assumption of unravelling theory, however, is that consumers know that providers have information to disclose. Little is known regarding how consumer expectations interact with a provider's disclosure decision. Are disclosure decisions different when a signal's influence diminishes or when consumers are unaware that information exists to disclose? The novel disclosure environments we explore allow us to address these questions. To our knowledge, no test of unravelling theory has compared disclosure when it is anticipated as opposed to when it is unexpected.

\section{Overview}

If ratings are important to consumers, should hotels advertise them? Many people have the intuition that they should do so only if the ratings are relatively favourable [17], but the logic of unravelling theory is that hoteliers should always display their rating, unless it is the very worst possible, in which case they should be indifferent whether they display them or not. To demonstrate this, consider the logical process of unravelling. What will a hotel do if it has the best possible rating of Five on TripAdvisor? Obviously, they will advertise this. If all hotels rated as Five disclose, the best non-disclosing hotels are those with a rating of Four and a half, who will disclose because they will not want to be pooled with lower rated hotels. The best non-disclosing hotels are then those with a rating of Four. It is evident that the same unravelling logic will continue to apply to hotels all the way down the hierarchy of ratings. Even hotels with the lowest rating will be indifferent between disclosing and not, because by not disclosing they implicitly reveal their rating is the lowest. Frank [18] has termed this the "full-disclosure principle", which states that when "some individuals benefit by revealing a favourable value of some trait, others will be forced to disclose their less favourable values".

Our results confirm that, with respect to TripAdvisor ratings, the full-disclosure principle does not hold. Many hotels, even those with very good ratings, do not disclose them. Moreover, when they do disclose there is a monotonic relationship between the rating and disclosure, a result that can best be described as partial unravelling. As we argue (and as others have argued—c.f., Sah \& Read [17]) it is unlikely that the logical argument just provided is driving this outcome.

Secondly, we observe lower overall rates of disclosure for international hotels, drawn from major global cities. We argue that this occurs because specific assumptions underlying 
unravelling theory are weakened for international hotels, and therefore the theoretical prediction is less likely to apply.

Thirdly, we demonstrate that TripAdvisor ratings are more likely to be disclosed in travel catalogues, a context in which non-disclosure is maximally salient because it is revealed by comparison with other disclosing hotels. This underlines the importance of context in eliciting disclosure. When it is easy for consumers to carry out the unravelling logic, the full disclosure principle is more likely to apply.

Fourthly, we offer further evidence concerning whether firms rely on reputation as opposed to third-party metrics. We consider the higher-end of the hotel market by evaluating the disclosure behaviour of elite establishments outside our primary dataset-this is a hypothesized behaviour where high quality types do not disclose to subtly communicate their confidence [19]. We only find partial evidence to support this. In our regional sample, the very finest hotels disclose less compared to elite hotels. This result is not, however, found in our international sample.

Finally, we show that disclosure decisions (outside our primary market) are nonstrategic in that they are made without consideration of anticipated consumer response to nondisclosure. We do this by comparing disclosure of TripAdvisor ratings by hotels with disclosures on a second much less familiar rating platform (TrustPilot).

\section{Disclosure and Unravelling Theory}

\subsection{Basic Theory and Effects}

Unravelling theory is central to strategic interactions where an agent who possesses information relevant to the decisions of another party can credibly (i.e., without lying) communicate that information in a costless way. As described above, an iterative sequence of inferences leads to an equilibrium prediction of full disclosure as "enterprises or individuals at the above-average end of the quality spectrum successively distinguish themselves from the group in a process that unravels from the top down" $[1]^{2}$. In theory, it is not even necessary for there to be other agents for the unravelling logic to apply. That is, even if there was only one hotel in existence that possessed a TripAdvisor rating, and consumers knew they possessed it, the logic of unravelling would apply. Critically, the unravelling principle depends on the response of consumers to non-disclosure, and on the awareness of information providers (the hotel manager) of that consumer response. It is assumed that consumers will judge non-disclosers in the worst possible light, and information providers will act accordingly by disclosing unless they are in fact the worst possible.

From a policy perspective, unravelling is appealing as it can improve consumer welfare without the need for legislation. For instance, rather than legislating hygiene standards, governments can provide restaurants with hygiene certificates which they can post voluntarily. Through unravelling, all restaurants with a hygiene rating higher than the minimum will post their ratings. Any restaurant with a missing rating will invariably have very poor hygiene, and consumers will know this. In short, the unravelling logic should guard against adverse selection [20,21]. Examples of the positive implications of high levels of disclosure include increased trust between buyers and sellers, improved market sorting (both horizontally and vertically), and the escalation of competitive pressures which can incentivise inferior agents to improve. Dranove \& Jin [22] provide a comprehensive review of the effects of disclosure, while Sah, Cain \& Loewenstein [23] provide insights into the perversions of mandatory disclosure policies.

As noted, the momentum for disclosure is premised on sellers revealing information because they believe consumers will interpret nondisclosure rationally. Whether consumers do this is dubious - a significant body of research has shown that individuals fail to appreciate, and commonly underestimate, nondisclosure (see Bazerman \& Moore [24] for an overview of these biases and Brown, Camerer \& Lovallo [25] for an original application). Considered solely in the context of disclosure, theoretical and experimental studies are adding greater weight to the view that consumers make non-optimal and excessively charitable inferences when information is withheld [26-28] 


\subsection{Empirical Tests of Unravelling Theory}

Unravelling theory has proven challenging to test, and few investigations exist. Field tests often rely upon a chance regulatory change to disclosure requirements, or some other variation in field conditions. Furthermore, empirical tests are scarce because historically centralised rating systems from which to voluntarily disclose positive traits did not exist. Even if such non-mandatory systems were available, there have been few (if any) practical methods to verify a disclosure. In the absence of a mechanism to verify costless claims, disclosures would remain unsubstantiated "cheap talk" [29]. Technological advances have allowed widely used rating systems to be established and for more detailed empirical research on unravelling theory. In particular, online commons such as TripAdvisor offer a medium for the dissemination of non-endogenous ratings scales.

The earliest test of unravelling theory is by Mathios [30] who used scanner data to study voluntary and mandatory disclosure for salad dressing in American markets after the 1990 Nutrition Labelling Act. He demonstrated a linear relationship between the likelihood of disclosure and fat content. Virtually all products with under $6 \mathrm{~g}$ of fat per serving disclosed, $60 \%$ of those with between 7 and $9 \mathrm{~g}$ of fat disclosed and only $20 \%$ of those with between 10 and $20 \mathrm{~g}$ disclosed. One limitation to this study is that not all consumers may hold a preference for less fat, which weakens the prediction of full unravelling.

Jin \& Leslie [31] took advantage of legal variations in disclosure requirements to study the effect of disclosure on hygiene quality regulation where disclosure was voluntary for one group and mandatory for another. They found that restaurants mandated to disclose their hygiene ratings improved their hygiene more than restaurants for which disclosure was voluntary. If voluntary disclosure was equivalent to mandated disclosure, as predicted by unravelling theory, both groups of restaurants would have felt the same pressure to disclose and to improve their hygiene.

Jin [32] studied disclosure by analysing accreditation reviews from 1991 to 1998 for Health Maintenance Organizations, a highly competitive market, finding incomplete voluntary disclosure. Less than half of the organisations disclosed, again contrary to the full-disclosure principle. Both these studies, however, concern conditions where consumer awareness of the undisclosed information may have been incomplete, and therefore full disclosure would not be inevitable, even from sophisticated providers.

Recent empirical tests of unravelling consider the possibility of 'false modesty' and countersignalling [33-35]. Luca \& Smith [33] measure disclosure decisions for MBA programs in American, finding that $65 \%$ of 240 business schools publish their ranking, but the most famous schools (e.g., Harvard and Wharton) countersignal by not disclosing. Bederson et al. [34] reveal a mixed pattern of signalling and countersignalling. They consider hygiene score card disclosures by restaurants and show that the highest performing end of the most hygienic restaurant category (A grade) tend to countersignal while lesser performers still within the best grade disclose.

\section{Disclosure and Hotels}

There are various practical reasons that make the hotel industry ideal for studying disclosure. First, the market for hotels is characterised by vertical product differentiation, with hotels differing greatly in the quality of service they offer. This is the basis for industry standards. Hotels must also satisfy a range of consumer needs, and TripAdvisor ratings reflect consumers' evaluations of the service. This will vary, even within a given certification. In short, this market offers a clear quality spectrum to test unravelling theory.

Second, hotels have limited ability to "game the system" that matches buyers with sellers. As hotels do not screen customers systematically, this is likely to increase the validity of user ratings. Additionally, selective gaming from hoteliers is less likely in the industry as the market is well-established. Unlike other sectors rated on TripAdvisor, such as restaurants, hotel markets are not subject to the same level of churn. Hotels incur high fixed costs, and the market is relatively stable ${ }^{3}$. 
Third, hotels have a high user turnover and there are many consumers available to provide ratings. Most are subject to high volume consumer reviews. As visits to hotels are repeated experience goods, with consumers staying at many hotels, one would expect guests to be able to compare across hotels and rate performance relative to past experiences. This increases the reliability of TripAdvisor ratings.

Finally, in contrast to many experience goods where tastes are idiosyncratic, we expect preferences for hotels to be well-behaved. Hotels have many primary quality dimensions where "better" is defined unambiguously. Virtually all customers prefer hygienic premises to unhygienic ones, polite staff to rude ones, larger rooms to smaller, and so on. Wellbehaved preferences are a prerequisite for the unravelling result-the dimensions under which hotels are reviewed by consumers is compatible with this assumption ${ }^{4}$.

\section{Empirical Framework}

To investigate unravelling, two requirements must be met. Firstly, hotels must be able to credibly report favourable traits to distinguish themselves. TripAdvisor ratings are easily disclosed and verifiable. These are a summated rating on an ordinal scale from 1 to 5 , where half unit ratings are possible. The ratings are derived from a collective assessment of all reviews and correspond to Excellent (5), Very Good (4), Average (3), Poor (2) and Terrible $(1)^{5}$. Second, an instrument to verify whether a trait is disclosed must exist. Due to the prevalence of digital reservations, hotel websites represent modern shop windows. These provide researchers with credible data on disclosure decisions.

We collected data by manually searching for TripAdvisor disclosures on each hotel's official website. We coded a hotel as disclosing if at least one of the following criteria was met: (i) the rating was explicitly published on the website or there was an inbuilt TripAdvisor review section; (ii) the rating was 'one-click-away' or there was a distinct (hyper)link to the hotel's TripAdvisor's webpage; (iii) a specific claim to a hotel's TripAdvisor performance was made. Examples are given in the Appendix A.

\subsection{Data}

We obtained TripAdvisor (non-) disclosures at regional and at international level. The regional sample comprised hotels in the United Kingdom and Ireland. To ensure a competitive market was in operation, the locations represented highly populated cities ${ }^{6}$. The international sample was drawn from the following cities, each a major tourist hub: London, New York, Paris, Rome, Singapore, Sydney, Tokyo. All the hotels were sourced from the TripAdvisor platform. Hostels, B\&Bs and lodges were excluded. All the hotels included held an industry star certification.

To be included in the dataset, a hotel needed at least 100 TripAdvisor reviews. This ensured the rating was reliable and minimised the possibility of deception. The fast pace of the industry (TripAdvisor widgets are updated daily) and the volume of reviews reduced the likelihood that gaming could systematically alter the ratings ${ }^{7}$. Data were accessed on hotel name, location, star certification, TripAdvisor rating, the number of reviews and the disclosure decision on the hotel's official website. All data were collected over two time periods in 2016 and 2017. In total, data were collected on 4357 hotels across 22 locations. These ratings were derived from 4,060,830 individual reviews submitted to TripAdvisor.

We also drew on three additional datasets. A holiday catalogue dataset allowed us to examine the importance of the reservation context and the presence of an intermediary agent on a TripAdvisor disclosure. With these data we tested if disclosure is more likely when information is easily comparable across providers [17]. The second dataset consisted of TripAdvisor rating disclosures from famous and award-winning hotels in the Forbes Travel Guide. This allowed us to consider if the world's best hotels choose to rely on reputation and ignore customers' evaluations. The third dataset was assembled from TrustPilot, a platform similar to TripAdvisor but much less well known (especially at the time we collected our data). While this dataset concerns a different market, it addresses a 
theoretical question-are disclosure decisions based on anticipated consumer responses to non-disclosure?

\subsection{Regional Data-United Kingdom E Ireland}

TripAdvisor ratings were obtained for 1490 hotels in sixteen UK and Ireland locations. We verified if these ratings were disclosed on their official websites. Fifteen hotels were excluded because they had non-operational websites or had been recently closed, leaving us with 1475. Table 1 summarises this regional dataset. The TripAdvisor ratings were based on 1,673,641 reviews. (minimum, 109; maximum, 12,702). We observed the following quality distribution: 5 (33 hotels), 4.5 (440 hotels), 4 (541 hotels), 3.5 (250 hotels), 3 (96 hotels) and $<3$ (115 hotels). Ratings of 3 or lower were categorised into a single category because they were rare.

Table 1. Descriptive Statistics—Regional Dataset.

\begin{tabular}{ccccc}
\hline Location & $\boldsymbol{N}$ & $\begin{array}{c}\text { Mean } \\
\text { Certification }\end{array}$ & $\begin{array}{c}\text { Mean TripAdvisor } \\
\text { Rating }\end{array}$ & $\begin{array}{c}\text { Mean No. } \\
\text { Reviews }\end{array}$ \\
\hline Belfast & 32 & 3.5 & 4.1 & 1295 \\
Birmingham & 78 & 3.2 & 3.8 & 990 \\
Cork & 22 & 3.7 & 4.2 & 1097 \\
Coventry & 26 & 3.2 & 3.6 & 695 \\
Dublin & 113 & 3.3 & 3.8 & 1272 \\
Edinburgh & 126 & 3.5 & 4.1 & 1085 \\
Galway & 31 & 3.5 & 4.1 & 1047 \\
Kerry & 63 & 3.7 & 4.3 & 748 \\
Leeds & 46 & 3.4 & 4.0 & 960 \\
Liverpool & 60 & 3.4 & 4.1 & 1345 \\
London & 686 & 3.5 & 3.8 & 1202 \\
Manchester & 72 & 3.4 & 3.9 & 823 \\
Newcastle & 44 & 3.3 & 4.0 & 752 \\
Nottingham & 33 & 3.2 & 3.7 & 777 \\
Sheffield & 30 & 3.3 & 4.0 & 789 \\
Waterford & 13 & 3.4 & 3.8 & 1134 \\
\hline Totals & 1475 & 3.4 & 3.9 & \\
\hline
\end{tabular}

\subsection{International Data}

Data were collected for hotels for seven major international cities. These included TripAdvisor ratings for 3658 hotels and verified disclosures for 3568. Table 2 summarises this international dataset. The TripAdvisor ratings for international hotels were based on 3,225,773 reviews (minimum, 100; maximum, 20,037). Consistent with the regional dataset, six specific class intervals were identifiable: 5 (74 hotels), 4.5 (1008 hotels), 4 (1300 hotels), 3.5 (730 hotels), 3 (270 hotels), <3 (186 hotels).

Table 2. Descriptive Statistics-International Dataset.

\begin{tabular}{ccccc}
\hline Location & $N$ & $\begin{array}{c}\text { Mean } \\
\text { Certification }\end{array}$ & $\begin{array}{c}\text { Mean TripAdvisor } \\
\text { Rating }\end{array}$ & $\begin{array}{c}\text { Mean No. } \\
\text { Reviews }\end{array}$ \\
\hline London & 686 & 3.5 & 3.8 & 1202 \\
New York & 372 & 3.6 & 4.2 & 1932 \\
Paris & 1277 & 3.3 & 3.9 & 509 \\
Rome & 755 & 3.3 & 3.8 & 619 \\
Singapore & 214 & 3.5 & 3.1 & 1290 \\
Sydney & 119 & 3.8 & 4.9 & 1406 \\
Tokyo & 145 & 3.2 & 3.9 & 574 \\
\hline Totals & 3568 & 3.4 & & 901 \\
\hline
\end{tabular}




\section{Analysis}

Two contrasting hypotheses are derived from unravelling theory and past empirical tests: full disclosure (strict theoretical prediction) and selective disclosure (behavioural prediction). Unravelling theory predicts all hotels will disclose except those with the worst TripAdvisor rating (who are indifferent between disclosing and not-disclosing). The second hypothesis had two parts: first, there are fewer TripAdvisor disclosures at every level of quality (less than full disclosure), and second, the disclosure rate declines monotonically as quality declines.

The first hypothesis can be safely rejected. For the combined datasets, the aggregate disclosure rate was only $43 \%$. The observed trend is compatible with the second hypothesis. Table 3 provides the disclosure rates for each TripAdvisor rating for the complete (merged) regional and international hotels.

Table 3. Disclosure Rate by TripAdvisor Category—Combined Dataset.

\begin{tabular}{ccccccc}
\hline TripAdvisor Rating & $\mathbf{5}$ & $\mathbf{4 . 5}$ & $\mathbf{4}$ & $\mathbf{3 . 5}$ & $\mathbf{3}$ & $<3$ \\
\hline Complete dataset disclosure (\%) & $67 \%$ & $55 \%$ & $48 \%$ & $29 \%$ & $16 \%$ & $5 \%$ \\
No. of Hotels & 83 & 1253 & 1642 & 856 & 319 & 204 \\
\hline$\chi^{2}$ & 4.61 & 13.82 & 84.28 & 18.77 & 16.34 & - \\
$p$-value & 0.03 & 0.00 & 0.00 & 0.00 & 0.00 & - \\
\hline
\end{tabular}

A Kruskal-Wallis test confirmed the differences in disclosure between the six categories $\left(\chi^{2}(5)=292.17, p=0.00\right)$. Additionally, we tested for differences between adjacent categories (i.e., 5 to $4.5,4.5$ to 4 ). The chi-square tests confirmed clear statistical differences between all adjacent rating intervals. Figure 1 displays the rates of disclosure (black bars) across the categories, compared to the strict prediction of full disclosure (white bars). For the lowest ratings, the prediction is either full disclosure or no disclosure, as indicated by the dashed line ${ }^{8}$.

Unravelling was similarly incomplete for the regional and international sample. Although $51 \%$ of regional hotels disclosed their TripAdvisor rating, this dropped to $41 \%$ for the international sample. As seen in Figure 1, voluntary disclosure decreased as TripAdvisor ratings fell. This supports the second hypothesis of non-random selective disclosure.

Regionally, over $80 \%$ of hotels holding a rating of 5 disclosed, but this fell monotonically to $34 \%$ for a rating of 3.5. It is interesting that several hotels rated 5 on TripAdvisor did not disclose. This is consistent with recent experimental evidence [17]). Only $5 \%$ of hotels receiving a TripAdvisor rating of 3 or lower disclosed a rating. Internationally, a similar trend was observed. Although this finding is largely consistent with theory, alternative motivations discussed later may explain the absence. Linearly declining disclosure was also observed in the international sample. As expected, we observed differences across the range of intervals for the disaggregated datasets for the regional $\left(\mathrm{KW}: \chi^{2}(5)=170.31\right.$, $p=0.00)$ and international $\left(\mathrm{KW}: \chi^{2}(5)=221.28, p=0.00\right)$ data. To consider threshold effects between rating intervals, Table 4 presents the disclosure proportions for each TripAdvisor rating, along with the results from chi-square tests comparing adjacent categories. As can be seen, the lower the TripAdvisor rating, the lower the probability of a disclosure.

\section{Estimating Disclosure}

To estimate the probability of a hotel making a disclosure and to build upon our descriptive analysis, we specified a basic probit model (Equation (1)). This specification remains consistent across the alternative estimations that follow. The dependent variable was categorical where DISCLOSURE $E_{T A}$ was 1 for a disclosure ( 0 otherwise). The covariates were dummy variables indicating if a TripAdvisor rating fell within a class interval. For the purposes of regression, the reference category consisted of hotels in the lowest rating category. Location fixed effects were included. 
Regional $(N=1475)$

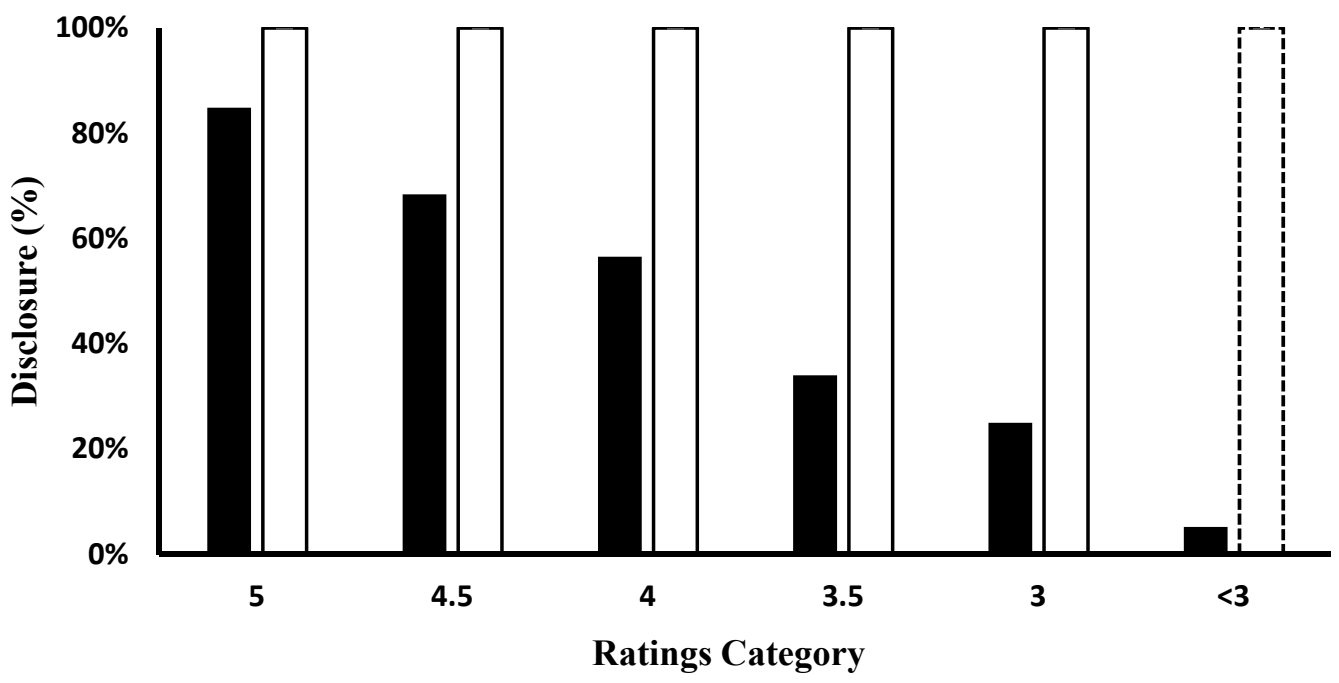

- Disclosure Rate $\quad$ Unravelling Prediction

International $(N=3568)$

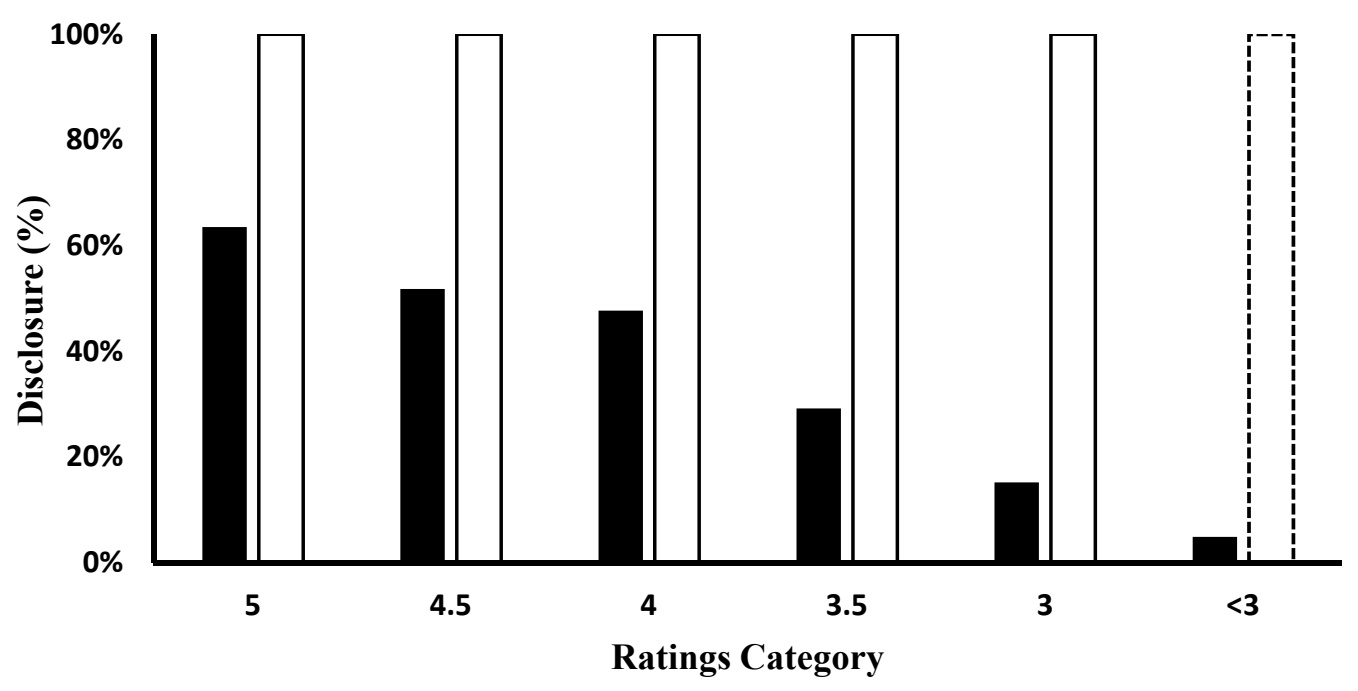

- Disclosure Rate $\quad$ Unravelling Prediction

Figure 1. Observed and predicted rating disclosures by TripAdvisor category.

Table 4. Disclosure Rate by TripAdvisor Category-Regional \& International.

\begin{tabular}{ccccccc}
\hline TripAdvisor Rating & $\mathbf{5}$ & $\mathbf{4 . 5}$ & $\mathbf{4}$ & $\mathbf{3 . 5}$ & $\mathbf{3}$ & $<3$ \\
\hline Regional disclosure $(\%)$ & $85 \%$ & $68 \%$ & $57 \%$ & $34 \%$ & $25 \%$ & $5 \%$ \\
$\chi^{2}(p$-value) & 3.91 & 14.18 & 35.64 & 2.55 & 16.78 & - \\
& $(0.05)$ & $(0.0)$ & $(0.0)$ & $(0.11)$ & $(0.0)$ & \\
\hline International disclosure $(\%)$ & $64 \%$ & $52 \%$ & $48 \%$ & $29 \%$ & $15 \%$ & $5 \%$ \\
$\chi^{2}(p$-value) & 3.80 & 3.81 & 66.22 & 20.36 & 12.07 & - \\
\hline
\end{tabular}


$\operatorname{DISCLOSURE} E_{T A}=\alpha_{0}+\beta_{1}($ rating 5$)+\beta_{2}($ rating 4.5$)+\beta_{3}($ rating 4$)+\beta_{4}($ rating 3.5$)+\beta_{4}($ rating 3$)+\beta_{5}($ rating $<3)+\beta_{5}($ Location $)+\varepsilon(1)$

Marginal effects for seven different samples, beginning with the entire dataset, are reported in Table 5 These results confirm how differences in disclosure vary in response to a ceteris paribus change in a covariate and identify the linearity apparent in Figure 1. A measure of localised fit is also reported ${ }^{9}$. As only two location effects are identified, these coefficients are not included in the results. The two incidences where hotel location statistically influenced disclosure (Paris and Rome) are subject to explicit analysis.

Table 5. Probit Results-Marginal Effects.

\begin{tabular}{|c|c|c|c|c|c|c|c|}
\hline $\begin{array}{c}\mathrm{OV}=<3 \\
\text { Hotels }\end{array}$ & & & & & & & \\
\hline $\begin{array}{c}\text { DV = } 1 \text { if } \\
\text { Disclosure, } 0 \\
\text { Otherwise }\end{array}$ & (I) & & (II) & & & (III) & \\
\hline Sample & Combined & UK \& Ireland & London & Provincial BI & International & Paris & Rome \\
\hline Rating 5 & $\begin{array}{c}0.755^{* * *} \\
(0.070)\end{array}$ & $\begin{array}{c}0.920 \text { *** } \\
(0.107)\end{array}$ & $\begin{array}{c}0.814^{* * *} \\
(0.111)\end{array}$ & $\begin{array}{l}- \\
-\end{array}$ & $\begin{array}{c}0.739^{* * *} \\
(0.075)\end{array}$ & $\begin{array}{c}0.601^{* * *} \\
(0.130)\end{array}$ & $\begin{array}{c}0.496^{* *} \\
(0.163)\end{array}$ \\
\hline Rating 4.5 & $\begin{array}{c}0.640 * * * \\
(0.050)\end{array}$ & $\begin{array}{c}0.729 * * * \\
(0.064)\end{array}$ & $\begin{array}{c}0.684^{* * *} \\
(0.071)\end{array}$ & $\begin{array}{c}0.727 * * * \\
(0.128)\end{array}$ & $\begin{array}{c}0.639 * * * \\
(0.057)\end{array}$ & $\begin{array}{c}0.402 * * * \\
(0.105)\end{array}$ & $\begin{array}{c}0.501^{* * *} \\
(0.110)\end{array}$ \\
\hline Rating 4 & $\begin{array}{c}0.577^{* * *} \\
(0.051)\end{array}$ & $\begin{array}{c}0.620 * * * \\
(0.065)\end{array}$ & $\begin{array}{c}0.681^{* * *} \\
(0.071)\end{array}$ & $\begin{array}{c}0.510 * * * \\
(0.131)\end{array}$ & $\begin{array}{c}0.607 * * * \\
(0.057)\end{array}$ & $\begin{array}{c}0.423 * * * \\
(0.104)\end{array}$ & $\begin{array}{c}0.475^{* * *} \\
(0.109)\end{array}$ \\
\hline Rating 3.5 & $\begin{array}{c}0.395^{* * * *} \\
(0.053)\end{array}$ & $\begin{array}{c}0.420 * * * \\
(0.071)\end{array}$ & $\begin{array}{c}0.446^{* * *} \\
(0.081)\end{array}$ & $\begin{array}{l}0.361 \text { * } \\
(0.139)\end{array}$ & $\begin{array}{c}0.431^{* * *} \\
(0.059)\end{array}$ & $\begin{array}{c}0.381^{* * *} \\
(0.106)\end{array}$ & $\begin{array}{c}0.264 \\
(0.114)\end{array}$ \\
\hline Rating 3 & $\begin{array}{c}0.242^{* * *} \\
(0.059)\end{array}$ & $\begin{array}{c}0.329 * * * \\
(0.082)\end{array}$ & $\begin{array}{c}0.308^{* * *} \\
(0.095)\end{array}$ & $\begin{array}{l}0.408 * \\
(0.159)\end{array}$ & $\begin{array}{c}0.258^{* * *} \\
(0.066)\end{array}$ & $\begin{array}{c}0.120 \\
(0.118)\end{array}$ & $\begin{array}{c}0.072 \\
(0.129)\end{array}$ \\
\hline $\mathrm{N}$ & 4357 & 1475 & 686 & 545 & 3568 & 1277 & 755 \\
\hline Pseudo $R^{2}$ & 0.07 & 0.12 & 0.16 & 0.08 & 0.09 & 0.03 & 0.08 \\
\hline
\end{tabular}

Significance level: $1 \%:{ }^{* * *} ; 5 \%{ }^{* *} ; 10 \% *$. All pooled regressions include location FE.

The first regression (I) in Table 5 displays the marginal effects for the entire dataset. Relative to the reference group $(<3)$, hotels rated from 3 to 5 were more likely to disclose their TripAdvisor rating. The likelihood of disclosure increased with the TripAdvisor rating; for the merged dataset, elite hotels (rated 5-excellent) were 75\% more likely to reveal their performance. The second series of estimates (II) shows the probability of a disclosure for regional hotels only. This allowed us to consider local and state specific effects $^{10}$. The highest rated hotels were $92 \%$ more likely to disclose relative to the worst for the complete regional sample-this is a clear trigger to initiate unravelling.

As London accounts for $46 \%$ of the regional data, it is considered separately (II). London represents a major international city and tourist hub, in comparison to smaller regional locations. The results for the London only subsample are consistent with the previous results. Hotels rated as excellent were the most likely to disclose relative to the base category. Hotels rated as second and third best respectively were equally likely to disclose. The final regression for the regional dataset focuses on provincial locations (Provincial BI). The results do not exhibit the exact linearity of the London results. While a strong statistical relationship exists between disclosure and TripAdvisor ratings for hotels rated as 4.5 and 4 , this weakens for lower ratings ${ }^{11}$.

The third series of estimates (III) considers the international dataset only. An international comparison provides an insight into the efficacy of the TripAdvisor signal outside the UK and Ireland. An analysis of major international destinations also allowed us to assess a homogenous cluster on a global scale. As previously shown, the rate of disclosure is lower when compared to the regional sample. We do, however, find a similar downward monotonic pattern. Similarly, robust statistical relationships are reported. 
Two specific spatial effects are apparent: hotels in Rome and Paris are between 12\% and $18 \%$ less likely to disclose. Given this finding, and as both Paris and Rome represent substantial subsamples, the second two regressions for the international estimates (III) investigate the likelihood of disclosure exclusively in these locations. For Paris, a recurrent downward disclosure relationship exists, but the rate of disclosure falls sharply for the second-best rating category (4.5). For Rome, a disclosure threshold is observed, with all hotels rated at 4 or above more likely to disclose. This decision approximates the same probability, $47.5 \%$ to $50 \%$, and is independent of the rating. These findings point toward the weakening power of the TripAdvisor signal outside the regional market.

\section{TripAdvisor Ratings and the Salience of Disclosure: The Case of Holiday Catalogues}

Hotel websites are standalone entities which display a great deal of heterogeneity in their design. This complexity can mask nondisclosure of TripAdvisor ratings, or any other information a hotel may choose to veil. In contrast, holiday catalogues-which also provide TripAdvisor ratings-present hotels in a homogeneous way. These are compiled by a third party and presented consecutively, meaning that variations in disclosure are salient. An example of this format for a disclosure and nondisclosure is provided in the Appendix A. In a holiday catalogue, the absence of a TripAdvisor rating is likely to be highly salient, and this will increase pressure to disclose.

To investigate whether this increased salience is associated with greater disclosure of TripAdvisor ratings, we collect data from two holiday catalogues-Thomson and Jet2Holidays. The Thomson catalogue consisted of hotels and resorts included in the 2017 Spain, Portugal and Cape Verde catalogue. All hotels and resorts in the Summer Holidays 2017 catalogue were considered for Jet2Holiday. Two critical assumptions underpin this analysis. First, we assume that hotels can affect the disclosure decision of the third party and that the presentation of information in catalogues will involve the agreement of hotels as well as catalogue editors. If hotels would prefer disclosure to be voluntary, they can negotiate this, but then highly-rated hotels would want to disclose their TripAdvisor ratings, and so the unravelling process would begin. Second, we assume that audiences of both online (website) and offline (catalogue) are equally sophisticated.

Data were available for 790 hotels across both catalogues for a total of thirty-two European destinations. In contrast to hotel websites, disclosure is almost complete. Except for minor omissions, the Thomson catalogue provides full disclosure: a TripAdvisor rating is included for all 179 hotels in the catalogue, including $6 \%$ with a rating of 3.5 or under. A TripAdvisor rating is not provided for a minority of hotels that were recently refurbished (4) or opened (5). In the absence of disclosure, a justification is offered (a refurbishment or new hotel symbol). A larger sample is available for 611 decisions from the Jet2Holiday catalogue. A disclosure rate of $97 \%$ is recorded. The distribution of hotels in the Jet2Holiday catalogues for each category was: 5 (8), 4.5 (228), 4 (280), 3.5 (84), 3 (9), <3 (2). Figure 2 displays the higher level of disclosure in this context for the Jet2Holiday sample and the minimal rate of nondisclosure in the lowest rated category.

To evaluate the likelihood of a catalogue disclosure, specific point estimates are obtained using the same specification adopted for the previous regressions. The rating categories of 3 and $<3$ were merged and used to enable comparisons with the TripAdvisor rating categories. Relative to these lowest rated hotels, those ranked greater than or equal to 3.5 were not more likely to exhibit selective disclosure (all $p^{\prime}$ s >0.17). As expected, there were no differences in this context, in which nondisclosure was highly salient (KW: $\left.\chi^{2}(4)=3.74, p=0.44\right)$. 


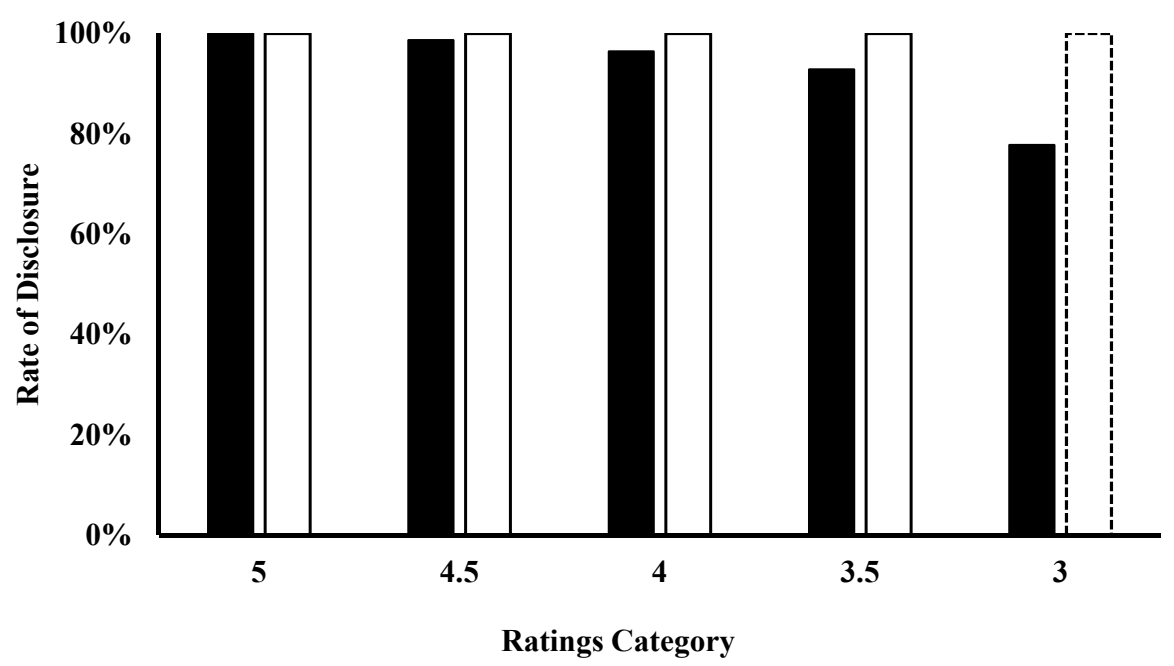

- Disclosure Rate $\quad$ Unravelling Prediction

Figure 2. Catalogue Disclosures-Jet2Holidays $(N=611)$.

\section{Nondisclosure and Motivations}

Although the strict predictions of unravelling theory fail, it is likely there are many reasons for the observed nondisclosure. Firstly, hoteliers could rely on their industry certification when TripAdvisor casts them in a light which is inconsistent with their star. These star certifications are not based on customer experience, but on factors such as food options, amenities, room sizes and other facilities (spas, gyms, etc.). The certification is coincidentally over the same numeric range as TripAdvisor, even though these scales are independent and do not necessarily reflect the same aspects of the business. This industry assessment could act as a reference point in determining disclosure. While these standards vary across markets, many hotels appear reluctant to disclose TripAdvisor ratings that do not match or exceed their certification. While it is important to restate that star certification and TripAdvisor ratings are on different scales, it is not improbable that consumers could conflate the measures, and that managers want to avoid this.

Secondly, managers may adopt general rules-of-thumb for TripAdvisor disclosures. For example, managers could believe consumers would interpret nondisclosure as equivalent to a 3 or 3.5 rating. If so, then no (or very few) hotels with that rating or less would disclose. While we do not have any evidence that general decision rules such as this exist within the industry, managers holding differing beliefs of what constitutes a reasonable rating for consumers could explain this pattern.

Secondly, strategic behaviour is a plausible explanation for the pattern of disclosure. Although nondisclosure should be equally revealing, ratings may not be disclosed if managers believe consumers will not interpret nondisclosure in the worst possible light. Recent experimental evidence suggests that consumers interpret undisclosed information "charitably". The optimal policy for service providers with an average rating is often to conceal it [17]. Assuming that hoteliers profit from nondisclosure at the expense of the consumer, the findings are consistent with models of limited strategic thinking. Brown et al. [25] argue that if sellers anticipate that consumers have very limited ability to make strategic inferences, providers will choose not to reveal information. This interpretation is strengthened by significantly higher levels of disclosure in an alternative sales setting; while these disclosures may be targeted at more sophisticated consumers, the elevated level of disclosure in catalogues indicates that the potential for hotels to behave strategically and obscure their TripAdvisor rating increases when disclosure choices deviate from set formats.

It is plausible that elite hoteliers choose to rely on reputation or branding rather than on third party rating systems. In the regional sample, $15 \%$ of hotels awarded the rare "excellent" rating did not disclose, as did $36 \%$ of the international sample. While this is only a small number of hotels, several elite premises choose to ignore their excellent (and rare) 
TripAdvisor rating. As discussed, recent research has shown that when luxury options exist in markets (e.g., education, restaurants), providers can adopt humble disclosure strategies by not sporting their elite credentials. As our context has ample luxury options with many well-established hotels, is it important to explore this possibility further.

To consider the possibility of systematic non-disclosure behaviour by the very best, we accessed data for hotels that are not merely elite but are also global leaders. Following the same procedure previously adopted, we verified 157 TripAdvisor disclosures for hotels certified as five stars and also included in the 2017 Forbes Travel Guide-Star Award Winners. These hotels were located across twenty-one countries globally. Of these exceptional hotels, $48 \%$ disclosed. This is a lower rate than that of the regional and international data for hotels rated as both 5 and 4.5. The Forbes Travel Guide contains 47 hotels with a five-star certification and the maximum TripAdvisor rating. While no statistical difference exists between the disclosure rates for the Forbes data and hotels in the international sample $\left(\chi^{2}=1.15, p=0.28\right)$, the disclosure rate varies from elite regional hotels $\left(\chi^{2}=9.72, p=0.00\right)$. Thus, compared to our regional sample, the most outstanding hotels, many of whom have a long history of excellence, appear to take exceptional reviews as a given, Either they do not see the need to disclose a TripAdvisor rating or believe it might be demeaning to do so.

\section{An Uncharted Motivation-Disclosure Expectations}

If consumers are confident that other consumers care about TripAdvisor ratings, and that the managers know this, then an undisclosed rating is worrying. But to the degree that consumers do not know what other consumers want, or what managers know, then a missing rating becomes increasingly ambiguous or has a low "signal value". In general, uncertainty concerning local norms, what others are expecting or how others value information can make non-disclosure less damaging, even from the perspective of strategically rational consumers.

A noticeable result is the higher rate of disclosure for regional hotels. There are possible rational explanations for this result, indicating disclosure motivations that fit within the theoretical framework of unravelling theory. One possibility derives from the concept of 'common knowledge' [36,37]. This entails that not only does every consumer know something, but they also know that all possible consumers know it too. In terms of unravelling theory and hotels, managers must believe that every consumer will want to know the TripAdvisor rating of their hotel and that every consumer knows that every consumer wants to know the rating. If common knowledge conditions are weakened, it becomes less crucial for a hotel to disclose because consumers will not know whether non-disclosure is due to low ratings, or because other consumers do not expect to see this information.

The common knowledge assumption is less likely to hold for international destinations that attract diverse consumers, compared to regional destinations which attract a more homogeneous group of consumers. With respect to international destinations, for instance, a consumer from New York booking a hotel in Tokyo will not be sure whether a guest from Rome seeks out TripAdvisor ratings. Notice that this is true even if the guests from Rome actually do want to see the TripAdvisor rating -if the New York traveller does not know this then she can interpret non-disclosure as being due to the hotel catering for guests from other destinations (see [37], for extensive discussion of this issue). Consumers from the relatively culturally homogeneous UK or Ireland, however, could be confident about local norms and what others from their region anticipate.

To analyse whether there is a difference in disclosure when disclosable information is recognised and when it is not, we introduced data from a market where the common knowledge assumption is unlikely to hold. By this, we are assuming that consumers have little to no knowledge that information concerning product quality exists to be disclosed. TrustPilot is a ratings provider much like TripAdvisor, but is relatively unfamiliar (especially when the study was conducted) and so consumers would not expect a Trust- 
Pilot rating from service providers. The differences in the strength of these signals are corroborated by comparing their 'interest over time' using Google Trends. We evaluate disclosures for non-bank financial service firms (NBFS) who received online appraisals from the review firm TrustPilot. This allowed us to measure if disclosure patterns vary when consumers are unlikely to realise there is an evaluation to disclose. Theoretically, unravelling will occur only when consumers know an evaluation exists, because only then can consumers recognise nondisclosure and expect other consumers to recognise it too. Consequently, ratings from unfamiliar platforms should be disclosed only when they are very high. Comparing disclosures allows us to consider naïve disclosure behaviour as both signals are of contrasting strength; the disclosure of known/anticipated (TripAdvisor) signals are compared to unknown/unexpected (TrustPilot) signals. If companies are thinking strategically about the response of customers, they should theoretically always disclose their TripAdvisor ratings, but will be cautious about disclosing their TrustPilot ratings.

At the time of data collection, TrustPilot users rated their experience on an ordinal quality scale from low (0) to high (10). We analyse these data as we did those for TripAdvisor $^{12}$. Verification took place for 489 firms. We classified the firms into half-unit rating intervals where adequate samples exist: 10-9.6 (114), 9.5-9.1 (164), 9-8.6 (91), 8.5-8.1 (39), $8-7(38), \leq 7$ (43). The total rate of disclosure across both the UK/Ireland and the USA was $63 \%$. Figure 3 shows the proportion of disclosures for the sample at each rating interval. A normative unravelling prediction is not included in Figure 3 given that we regard the TrustPilot signals not to be anticipated by a consumer.

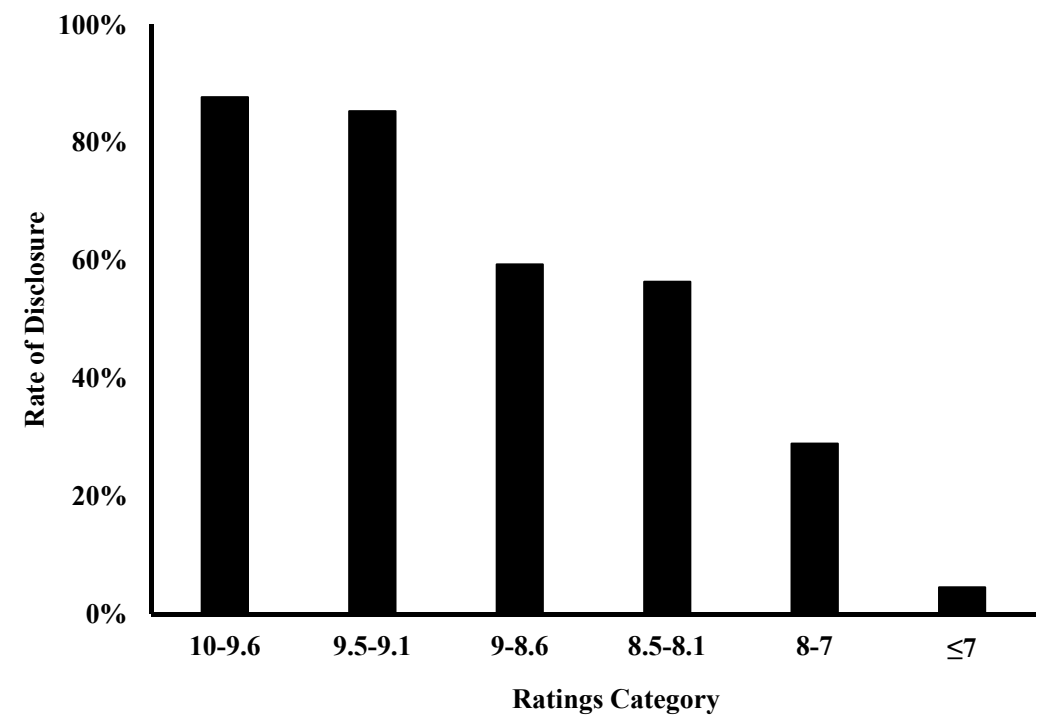

Figure 3. Rating Disclosures by Trustpilot Category.

The aggregate pattern is similar to that for TripAdvisor ratings (see Figure 1$)^{13}$, showing the same monotonically decreasing disclosure relationship. As expected, at least one category stochastically dominates another in Figure $3\left(\mathrm{KW}: \chi^{2}(5)=83.80, p=0.00\right)$. Chi-square tests reveal differences across the disclosure proportions-first and second categories $\left(\chi^{2}=10.53, p=0.01\right)$, second and third $\left(\chi^{2}=3.81, p=0.05\right)$, fourth and fifth $\left(\chi^{2}=3.82\right.$, $p=0.05)$ and fifth and sixth $\left(\chi^{2}=8.83, p=0.00\right)$. To yield specific probabilistic estimates regarding the likelihood of a disclosure, we have specified a similar probit model to the previous regressions ${ }^{14}$. Relative to the worst ranked firms (omitted category), firms ranked in the highest category of $10-9.6$, are $88 \%$ more likely to disclose their Trustpilot rating $(\mathrm{RSE}=0.089, p=0.00)$. The monotonic relationship observable in Figure 3 is recognised in the point estimates: the second category is $70 \%$ more likely to disclose ( $R S E=0.091, p=0.00)$ and the third and fourth are 59\% (RSE $=0.098, p=0.00)$ and 55\% (RSE $=0.109, p=0.00)$ more likely to disclose, respectively. Relative to the lowest category, those ranked 8-7, in 
the second lowest class interval, are $37 \%$ more likely to disclose a $5 \%$ level (RSE $=0.115$, $p=0.02$ ).

Those with high TrustPilot ratings generally disclose, those with low ratings generally do not. This suggests the basis for disclosure is not primarily determined by concerns regarding how consumers will respond to non-disclosure, but rather to how consumers will react to what is disclosed. If managers believe that the information they hold is not good enough, they do not disclose it. These findings are consistent with Sah \& Read ([17], who show that when asked to justify (non-) disclosure, respondents were concerned almost entirely with the impression made by disclosed information, and rarely discussed the impact of undisclosed information.

\section{Theoretical Discussion}

There are many situations in which information providers can make it easy for consumers to acquire relevant information, or to make it difficult. This is the kind of situation we studied. TripAdvisor ratings are available to consumers, but they may not bother to look them up. In contrast to Mathios [30], therefore, the nondisclosures we observe arise not in a situation of pure asymmetric information, but in one of unbalanced information. Despite this, the unravelling argument still holds. By imposing differential costs on different classes of information, managers make it easier for consumers to access some information and harder to access other information. Even putting features at the top of a list makes it more likely consumers will choose an option based on that feature. Managers will do this because they want consumers to choose based on their strongest characteristics and may want to hide or shroud less favourable features. Not listing a feature at all is the logical culmination of this reasoning.

Can nondisclosure be explained without proposing failures of strategic rationality on the part of either information providers or consumers? Unravelling depends on several conditions. All participants (managers and consumers) must be strategically rational. Managers must be able to credibly provide information to consumers at no cost. All consumers must have the same order of preferences concerning that information. Moreover, there must be common knowledge: if some participants do not believe these conditions apply, they may rationally make what appear to be non-equilibrium choices. In turn, this can change the optimal choice for other service providers. Similarly, random choices by some change the rational choices of others. For instance, if consumers do not punish nondisclosure, then a rational manager will withhold information. If some hotels do not disclose, then managers who might otherwise disclose can hide themselves in the thicket of non-disclosers. If non-equilibrium nondisclosures are frequent, then information receivers are sensible to treat non-disclosers as 'not as bad' as those who disclose a relatively low rating.

Consider the disclosure choice of a single five-star hotel with TripAdvisor rating of four. Assume the manager believes consumers are fully rational but is faced with a market in which others have made the disclosure decisions summarized in our study. The average TripAdvisor ratings of non-disclosing five-star hotels is approximately 4.1. A rational consumer will infer this as the expected quality. Even a somewhat risk averse consumer might rationally choose a non-disclosing five-star hotel over a disclosing five-star hotel with a TripAdvisor rating of four. It is plausible that an equilibrium emerges in which hotels with high TripAdvisor ratings are not disclosing them.

This explanation does not address why a hotel with a TripAdvisor rating of five might not disclose. Unravelling theory assumes that managers care only about ensuring consumers reach the most favourable assessment of their service, and, crucially, that they can do this through disclosing information. It is possible, however, that managers might not disclose because they believe that the very act of disclosure is demeaning, or have some other principled basis for non-disclosure. Some hoteliers may have preferred not to disclose TripAdvisor ratings for these arguably rational reasons. Any 'noise' in the disclosure environment produced in this way changes the context for other hoteliers and 
hoteliers and consumers, making nondisclosure a more viable option for the former, and charitable options more credible for the latter. In sum, exotic disclosure strategies adopted by elite types could interfere with the information environment for the population of potential disclosers.

Nondisclosure may also be a preferred strategy for managers because the worst information that could be inferred remains in the imagination of consumers. Even hotels with very good ratings, if delved into deeply, can be associated with a minority of poor reviews that might tarnish the hotel's reputation. Disclosure of positive information may direct consumers to small blotches on an otherwise immaculate copybook. This effect of salient reality could be a powerful reason for not disclosing even when theory says managers should.

\section{Conclusions and Implications}

This paper contributes to the strategic disclosure (and non-disclosure) literature by investigating a fast-paced consumer market. We investigate TripAdvisor disclosures regionally and internationally. We report monotonic disclosure relationships, with hotels more likely to disclose higher TripAdvisor ratings. Consistent with past studies, we find that the full disclosure prediction is incomplete. The average TripAdvisor rating of disclosing hotels is not substantially greater than that of non-disclosing ones. This implies a failure of unravelling theory. Notably, even the highest TripAdvisor ratings were not disclosed in every case. We also detect an interaction between TripAdvisor rating disclosures and a hotel's star certification; five- and four-star hotels are reluctant to disclose TripAdvisor ratings numerically below their star certification.

Our additional data provides further insights. Firstly, TripAdvisor ratings are almost always revealed in catalogues, when their absence would be salient due to the immediate comparability of other hotels. This result reinforces the importance of the sales context in regulating disclosure. Secondly, a small cohort of elite hotels do not disclose their excellent TripAdvisor ratings. When we investigated the disclosure behaviour of the most prestigious internationals, this pattern persists. Finally, we make a theoretical point relating to consumers' prior knowledge of signals. We control for expectations and identify a similar disclosure pattern with an analogous but unfamiliar rating platform. We take this as evidence that, even if consumers are not anticipating a disclosure, similar patterns arise.

Irrespective of the motivations underlying non-disclosure, failing to provide consumers with relevant information can have practical implications. Given the limited number of lower rated hotels that disclose, the results have consequences for consumer groups. As suggested, whether or not consumers can infer the implications of nondisclosure is highly questionable. Behavioural decision research has identified that individuals face psychological barriers when required to interpret missing information rationally. Thus, advocating consumer caution in online markets and emphasising the importance of seeking additional information (i.e., incurring greater search costs) is a clear recommendation emerging from the findings.

Finally, our results have theoretical implications for unravelling theory. The results posit questions for researchers who evaluate the strength of signals in markets, and their expectation by a signal receiver. While we show that common signals generally diffuse in similar patterns, different shades of disclosure are present across markets. One can only speculate why this is the case-anticipation of signals, culture or language differences may play a role. Our comparison of signals based on the alternative feedback platform TrustPilot indicates that anticipation of a signal appears to be independent of the disclosure decision whenever a quality range exists. Whether anticipated or not, it is unlikely that unflattering information will be disclosed unless nondisclosure is highly salient.

It is important to note the limitations of this study and directions for future research. Firstly, our extensive dataset and subsequent test is possible due to publicly available information; while the information environment investigated can be thought of as unbalanced rather than asymmetric, any imperfections to the information structure can be 
remedied by a savvy consumer willing to incur search costs. Hence, while significant datasets can be assembled, the strength of this test is limited. Acquiring data on differential search costs for consumers and how they go about gathering information could offer stronger demand-side implications. As such, only limited inferences can be made when interpreting the motivations for nondisclosure, and we simply offer interpretations for the pattern observed.

Secondly, we do not offer any insights regarding how a manager's expectations of consumer sophistication relate to disclosure. This omission raises interesting questions for future research as hotel disclosure decisions may relate to how hotels estimate the shrewdness of their market and the extent to which they are willing to incur search costs. It would be a fruitful exercise to understand the managerial beliefs of consumers through accessing survey data. Furthermore, we assume that managers hold decision making autonomy for marketing operations. These limitations suggest various avenues for future research.

Author Contributions: Conceptualization, D.B. and D.R.; methodology, D.B. and D.R.; software, D.B validation, D.B. and D.R.; formal analysis, D.B.; investigation, D.B and D.R.; resources, D.B and D.R.; data curation, D.B.; writing—original draft preparation, D.B. and D.R writing—review and editing, D.B. and D.R.; visualization, D.B.; supervision, D.R.; project administration, D.B. and D.R.; funding acquisition, D.R. All authors have read and agreed to the published version of the manuscript.

Funding: Daniel Read acknowledges the assistance of the Economic and Social Research Council [grant number ES/P008976/1].

Institutional Review Board Statement: Not applicable.

Informed Consent Statement: Not applicable.

Data Availability Statement: Please contact David Butler for data information.

Acknowledgments: The authors wish to acknowledge the contributions made to this paper by Sunita Sah, Andrea Isoni and Peter Ayton.

Conflicts of Interest: The authors declare no conflict of interest.

\section{Appendix A}

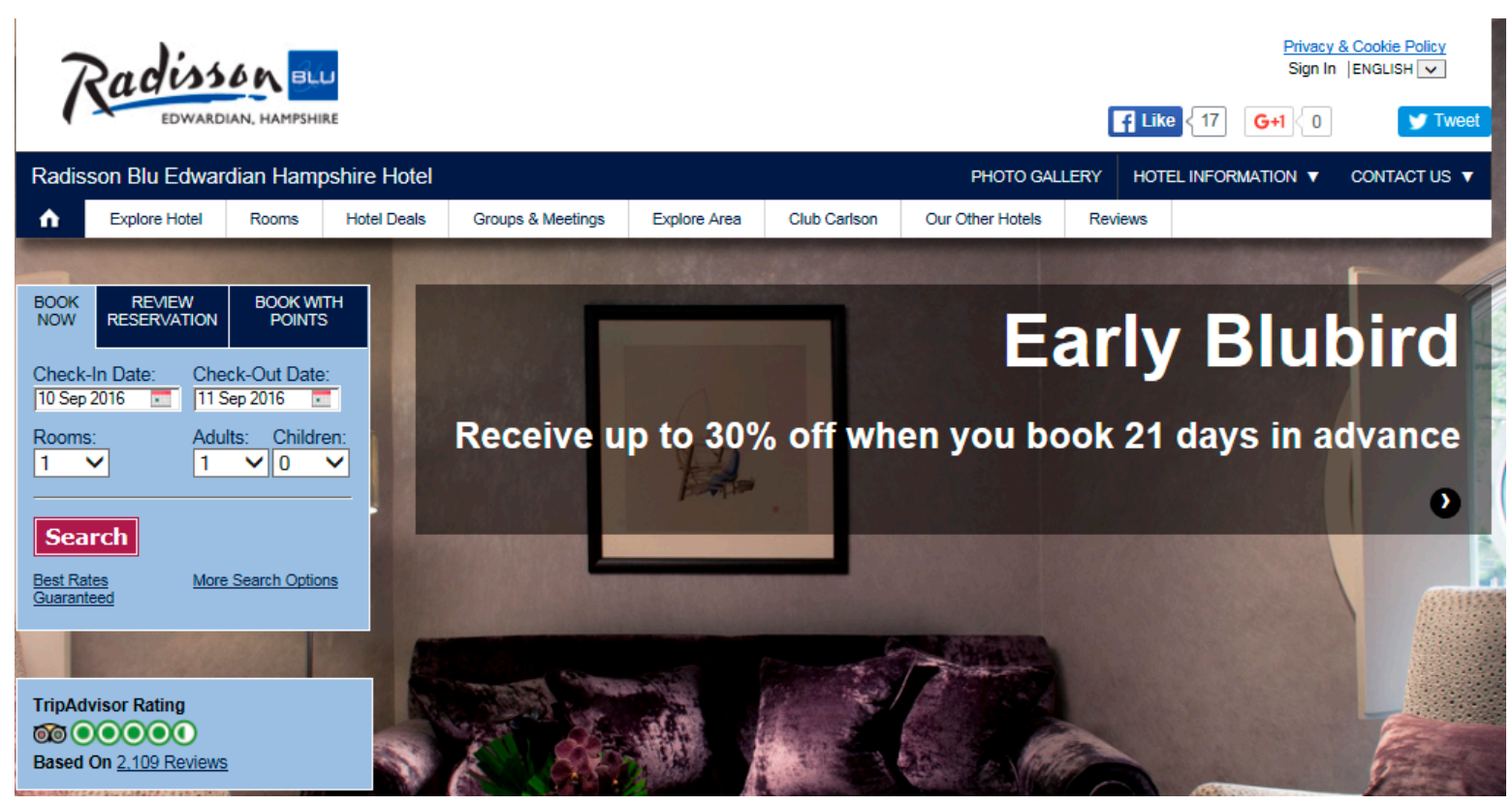

Figure A1. The rating is explicitly published on the website. 


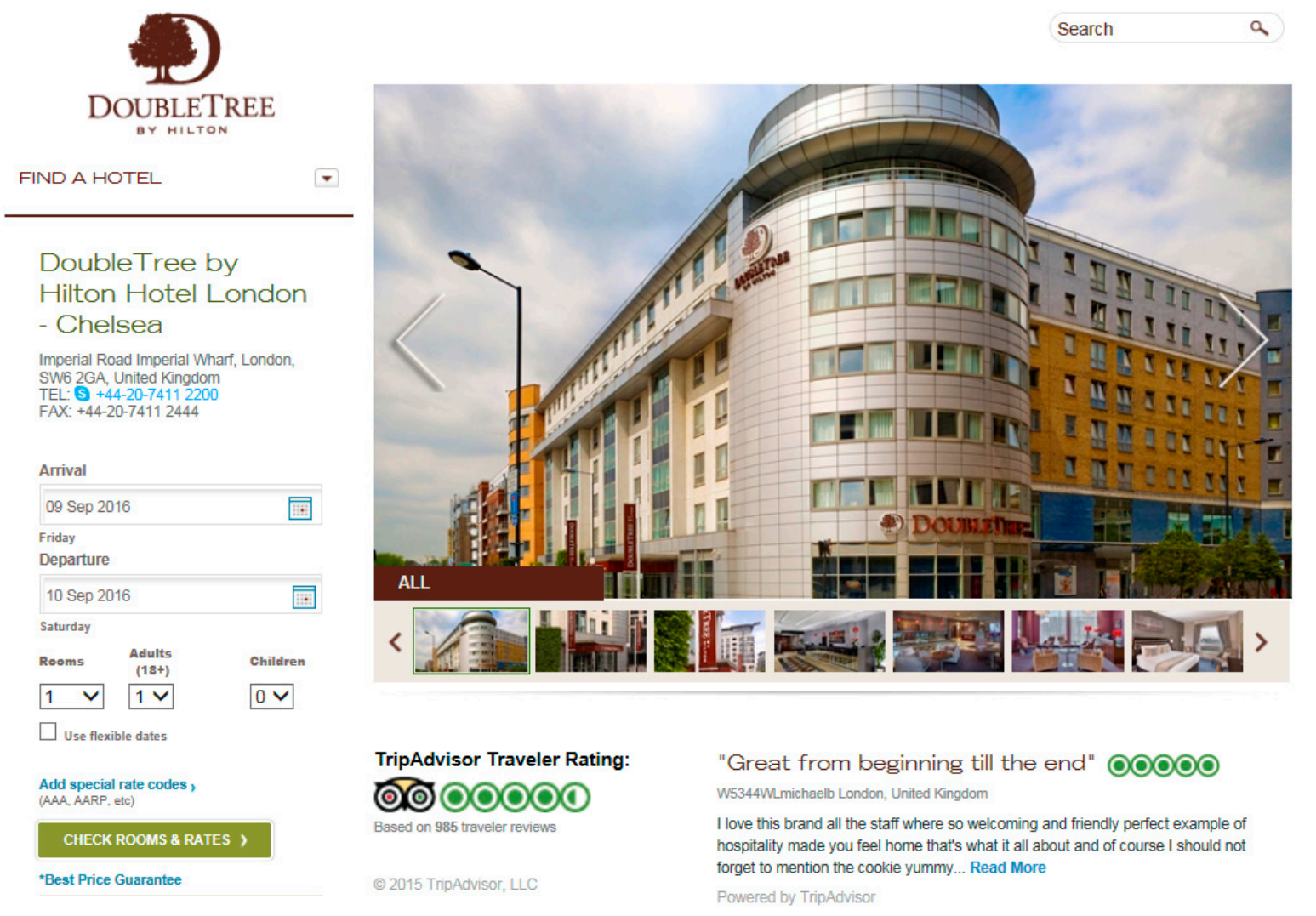

Figure A2. The rating is 'one-click away' or a distinct link exists to their TripAdvisor rating.
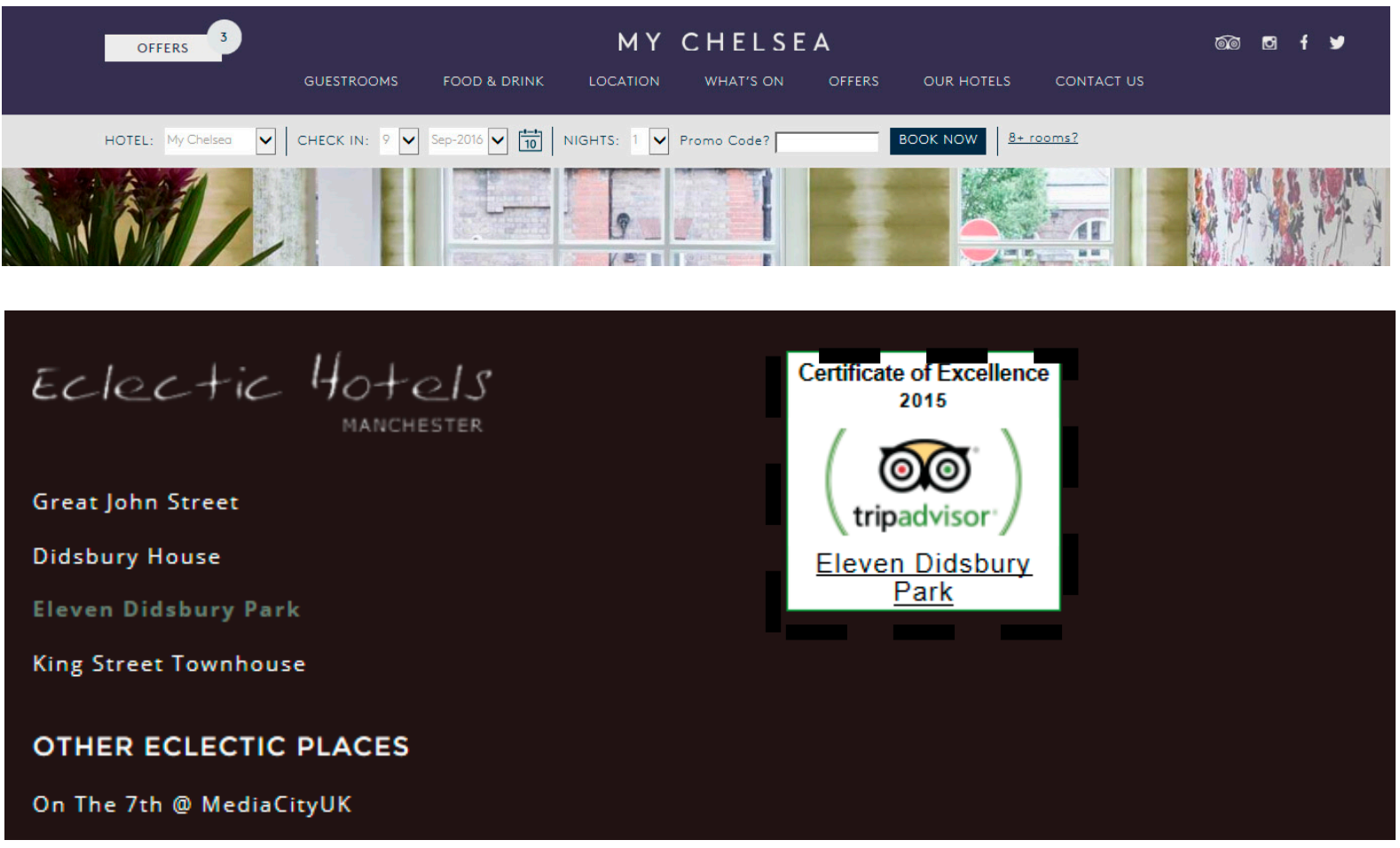

Figure A3. A specific claim to TripAdvisor reviews and performance on the website are made via an inbuilt section of the website. 

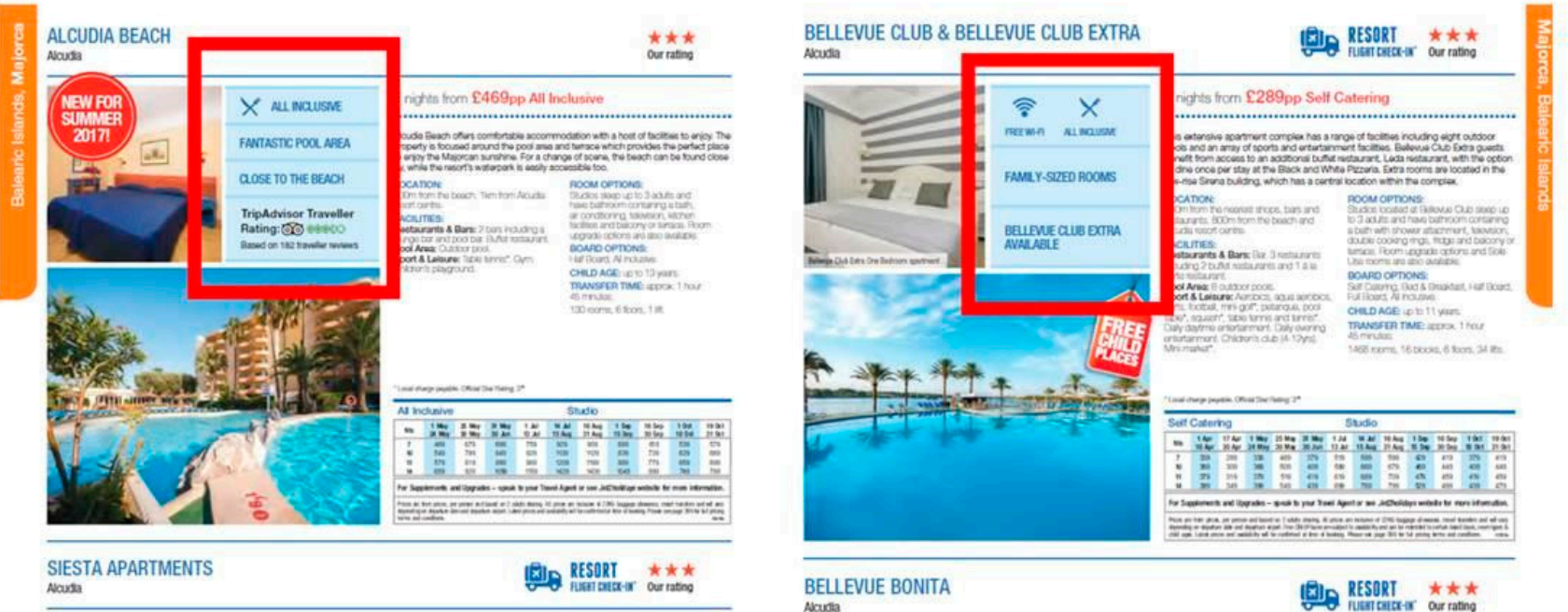

Figure A4. Disclosure (left) and nondisclosure (right) in the context of holiday catalogues.

\section{Notes}

1 In the UK, the sector is the third biggest employer. In 2017 it generated over 72 billion of gross added value to the UK economy (Ignite Economics, 2018) [38].

2 Riley [7] provides a formal treatment of information revelation and the unravelling result.

3 To our knowledge, all TripAdvisor hoaxes have involved restaurants and contexts where premises have been subject to limited public scrutiny.

4 Note that this is not always true for all domains investigating disclosure. With salad dressing, to give one example, it is likely that some consumers prefer high fat dressings while others prefer low fat dressings.

5 The summated rating for a hotel offered by TripAdvisor is more sophisticated than an average rating of all contributions. The system incorporates ratings to determine overall satisfaction, which is weighted based on the recency of a review.

6 One exception was made. Kerry is not a city but is a primary tourist region in the Republic of Ireland.

7 TripAdvisor have specifically developed a content integrity policy to protect against fraudulent reviewer behaviour. They guarantee that "businesses are not able to influence TripAdvisor to improve their reviews, ratings or ranking" This policy can be accessed online at https:/ / www.tripadvisor.ie/pages/content_integrity_policy.html (accessed on 19 May 2018).

8 For illustrative purposes, hotels ranked less than three are treated as being the "lowest", and hence the ratings at which a hotel should, according to the full disclosure prediction, be indifferent between disclosing or not disclosing. Technically, however, only the lowest possible ratings (1.5) should be indifferent to disclosure. Only four hotels in the dataset, however, received this rating.

9 Diagnostic checks on all regressions were conducted to ensure that the model is appropriately specified. A link test on each probit regression reports non-significant results ( $p>0.90$ for all regressions), indicating that the generalised model does not suffer from systematic specification errors.

10 For instance, the Irish government historically charged a lower VAT rate of $9 \%$ on tourist-related services. Given the sample size of Irish hotels, it is not feasible to estimate a probit regression. It is noteworthy that evaluating the unravelling principle for both Irish and UK markets using a linear probability model (LPM) reports analogous results. Analysing just the Irish market alone with a LPM, reveals a similar linear relationship to that of the UK sample. All Irish hotels rated as 5 make a voluntary disclosure, while hotels with a rating of $4.5,4$ and 3.5 have voluntary disclosure rates of $63 \%, 51 \%$ and $17 \%$, respectively. None of the lowest ranked Irish hotels (all rated 3.5) make a disclosure.

11 Rating 5 is dropped from this analysis as it produces a perfect prediction for the dependent variable.

12 For an admission to occur, a firm must fulfil at least one of the two criteria: (i) they explicitly publish their TrustPilot rating on their homepage or (ii) they refer to their TrustPilot performance. Data were accessed on 504 NBFS firms. Seven specific product categories were identifiable: pension/investment (57); insurance (138); short term personal and business loans (124); debt services and tax advisory (48); currency and exchange (75) and firms such as price comparison, credit score or switching services (47).

13 The rates of disclosure for the UK/Irish sample are: 88\% (10-9.6), 80\% (9.5-9.1), 61\% (9-8.6), 57\% (8.5-8.1), 27\% (8-7) and 0\% $(\leq 7)$. For the U.S., the rates of disclosure are: 72\% (10-9.6), 55\% (9.5-9.1), 56\% (9-8.6), 55\% (8.5-8.1) and 38\% $(\leq 8)$.

14 An addition to the model is that it introduces a vector of controls relating to the primary product of the firm. No significant results are reported for firms offering alternative financial products. 


\section{References}

1. Viscusi, W.K. A note on "lemons" markets with quality certification. Bell J. Econ. 1978, 9, 277-279. [CrossRef]

2. Grossman, S.J. The Informational Role of Warranties and Private Disclosure about Product Quality. J. Law Econ. 1981, 24, 461-483. [CrossRef]

3. Milgrom, P.R. Good News and Bad News: Representation Theorems and Applications. Bell J. Econ. 1981, 12, 380. [CrossRef]

4. Jovanovic, B. Truthful Disclosure of Information. Bell J. Econ. 1982, 13, 36. [CrossRef]

5. Farrell, J. Voluntary disclosure: Robustness of the unraveling result, and comments on its im-portance. In Antitrust and Regulation; Grieson, R.E., Ed.; Lexington Books: Lanham, MD, USA, 1986.

6. Milgrom, P. What the Seller Won't Tell You: Persuasion and Disclosure in Markets. J. Econ. Perspect. 2008, 22, 115-131. [CrossRef]

7. Riley, J.G. Essential Microeconomics; Cambridge University Press: Cambridge, UK, 2012.

8. Bergh, D.D.; Connelly, B.L.; Ketchen, D.J., Jr.; Shannon, L.M. Signalling theory and equilibrium in strategic management research: An assessment and a research agenda. J. Manag. Stud. 2014, 51, 1334-1360. [CrossRef]

9. Vermeulen, I.; Seegers, D. Tried and tested: The impact of online hotel reviews on consumer consideration. Tour. Manag. 2009, 30, 123-127. [CrossRef]

10. Jeacle, I.; Carter, C. In TripAdvisor we trust: Rankings, calculative regimes and abstract systems. Account. Organ. Soc. 2011, 36, 293-309. [CrossRef]

11. Sparks, B.A.; Browning, V. The impact of online reviews on hotel booking intentions and percep-tion of trust. Tour. Manag. 2011, 32, 1310-1323. [CrossRef]

12. Casaló, L.V.; Flavián, C.; Guinalíu, M.; Ekinci, Y. Do online hotel rating schemes influence booking behaviors? Int. J. Hosp. Manag. 2015, 49, 28-36. [CrossRef]

13. Park, S.; Nicolau, J.L. Asymmetric effects of online consumer reviews. Ann. Tour. Res. 2015, 50, 67-83. [CrossRef]

14. Torres, E.N.; Singh, D.; Robertson-Ring, A. Consumer reviews and the creation of booking transac-tion value: Lessons from the hotel industry. Int. J. Hosp. Manag. 2015, 50, 77-83. [CrossRef]

15. Xie, K.L.; Chen, C.; Wu, S. Online consumer review factors affecting offline hotel popularity: Evidence from tripadvisor. J. Travel Tour. Mark. 2016, 33, 211-223. [CrossRef]

16. Viglia, G.; Minazzi, R.; Buhalis, D. The influence of e-word-of-mouth on hotel occupancy rate. Int. J. Contemp. Hosp. Manag. 2016, 28, 2035-2051. [CrossRef]

17. Sah, S.; Read, D. Mind the (information) gap: Strategic nondisclosure by marketers and interven-tions to increase consumer deliberation. J. Exp. Psychol. Appl. 2020, 26, 432. [CrossRef] [PubMed]

18. Frank, R.H. Passions within Reason: The Strategic Role of the Emotions; Norton: New York, NY, USA, 1988.

19. Feltovich, N.; Harbaugh, R.; To, T. Too Cool for School? Signalling and Countersignalling. RAND J. Econ. 2002, 33, 630. [CrossRef]

20. Akerlof, G.A. The Market for "Lemons": Quality Uncertainty and the Market Mechanism. Q. J. Econ. 1970, 84, 488-500. [CrossRef]

21. Dye, R.A.; Finn, M. Equilibrium Voluntary Disclosures When Firms Possess Random Multi-Dimensional Private Information. In Essays in Accounting Theory in Honour of Joel S. Demski.; Antle, R., Liang, P.J., Gjesdal, F., Eds.; Springer: New York, NY, USA, 2007; pp. 53-72.

22. Dranove, D.; Jin, G.Z. Quality Disclosure and Certification: Theory and Practice. J. Econ. Lit. 2010, 48, 935-963. [CrossRef]

23. Sah, S.; Cain, D.M.; Loewenstein, G. Confessing one's sins but still committing them: Transparency and the failure of disclosure. In Behavioural Public Policy; Oliver, A.J., Ed.; Cambridge University Press (CUP): Cambridge, UK, 2014; pp. 148-164.

24. Bazerman, M.H.; Moore, D.A. Judgment in Managerial Decision Making; John Wiley \& Sons, Inc.: Hoboken, NJ, USA, 2009.

25. Brown, A.; Camerer, C.F.; Lovallo, D. To Review or Not to Review? Limited Strategic Thinking at the Movie Box Office. Am. Econ. J. Microecon. 2012, 4, 1-26. [CrossRef]

26. Loewenstein, G.; Sunstein, C.R.; Golman, R. Disclosure: Psychology Changes Everything. Annu. Rev. Econ. 2014, 6, 391-419. [CrossRef]

27. Ispano, A.; Schwardmann, P. Behavioural Economics. Competition over Cursed Consumers, CE-Sifo Working Paper Series, No. 7046. 2017. Available online: https://www.cesifo.org/en/publikationen/2018/working-paper/competition-over-cursedconsumers (accessed on 19 May 2018).

28. Sah, S.; Read, D. Disclosure and the Dog That Didn't Bark: Consumers Are Too Forgiving of Missing Information. Acad. Manag. Proc. 2017, 1, 12839. [CrossRef]

29. Farrell, J.; Rabin, M. Cheap Talk. J. Econ. Perspect. 1996, 10, 103-118. [CrossRef]

30. Mathios, A.D. The Impact of Mandatory Disclosure Laws on Product Choices: An Analysis of the Salad Dressing Market. J. Law Econ. 2000, 43, 651-678. [CrossRef]

31. Jin, G.Z.; Leslie, P. The Effects of Information on Product Quality: Evidence from Restaurants Hy-giene Report Cards. Q. J. Econ. 2003, 118, 409-451. [CrossRef]

32. Jin, G.Z. Competition and disclosure incentives: An empirical study of HMOs. RAND J. Econ. 2005, 36, 93-112. [PubMed]

33. Luca, M.; Smith, J. Strategic disclosure: The case of business school rankings. J. Econ. Behav. Organ. 2015, 112, 17-25. [CrossRef]

34. Bederson, B.B.; Jin, G.Z.; Leslie, P.; Quinn, A.J.; Zou, B. Incomplete Disclosure: Evidence of Signal-ing and Countersignaling. Am. Econ. J. Microecon. 2016, 10, 41-66. [CrossRef]

35. Harbaugh, R.; To, T. False modesty: When disclosing good news looks bad. J. Math. Econ. 2020, 87, 43-55. [CrossRef]

36. Lewis, D. Convention; Harvard University Press: Cambridge, MA, USA, 1969. 
37. Chwe, M.S.Y. Rational Ritual: Culture, Coordination, and Common Knowledge; Princeton University Press: Princeton, NJ, USA, 2001.

38. Ignite Economics. The Economic Contribution of the UK Hospitality Industry. 2018. Available online: https://www.ukhospitality. org.uk/page/EconomicContributionoftheUKHospitalityIndustry2018 (accessed on 4 November 2018). 